\title{
Endovascular management of cerebral venous sinus thrombosis
}

\author{
Omar Choudhri, M.D., Abdullah Feroze, B.S., Michael P. Marks, M.D., \\ AND HuY M. Do, M.D. \\ Department of Neurosurgery \& Interventional Neuroradiology, Stanford University Medical Centre, Stanford, \\ California
}

Cerebral venous sinus thrombosis (CVST) is characterized by formation of widespread thrombus within the cerebral venous sinus system. CVST can cause venous hypertension, venous infarcts, hemorrhage and seizures. It is managed in most cases with systemic anticoagulation through the use of heparin to resolve the thrombus. Patients that demonstrate clinical deterioration while on heparin are often treated with endovascular strategies to recanalize the sinuses. We present the case of a patient with widespread CVST, involving his superior sagittal sinuses and bilateral transverse sigmoid sinuses, who was treated with a combination of endovascular therapies.

The video can be found here: http://youtu.be/w3wAGIT7h8c.

(http://thejns.org/doi/abs/10.3171/2014.V2.FOCUS14186)

KEY WorDS $\bullet \quad$ venous sinus thrombosis $\bullet \quad$ mechanical thrombectomy $\bullet$
suction thrombectomy $\quad \bullet \quad$ balloon embolectomy $\bullet \quad$ endovascular $\bullet \quad$ video

Manuscript submitted May 3, 2014.

Accepted June 3, 2014.

Please include this information when citing this paper: DOI: 10.3171/2014.V2.FOCUS14186.

Address correspondence to: Omar Choudhri, M.D., Department of Neurosurgery, Stanford University School of Medicine, 300 Pasteur Drive MC5327, Stanford, California. email: ochoudhri@stanford. edu. 